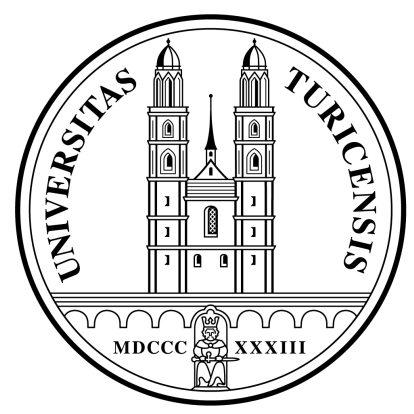

Institute for Empirical Research in Economics

University of Zurich

Working Paper Series

ISSN 1424-0459

Working Paper No. 105

Benefit Entitlement and the Labor Market:

Evidence from a Large-Scale Policy Change

Rafael Lalive and Josef Zweimüller

January 2002 


\title{
Benefit Entitlement and the Labor Market: \\ Evidence from a Large-Scale Policy Change
}

\author{
Rafael Lalive, University of Zurich, CESifo, and IZA \\ Josef Zweimüller, University of Zurich, CESifo, IZA, and CEPR*
}

January 25, 2002

\begin{abstract}
This paper analyzes the impact of the Austrian Regional Extended Benefit Program (REBP) on the labor market outcomes for elderly workers in Austria. The REBP extended entitlement to regular unemployment benefits from 30 weeks to a maximum of 209 weeks for elderly individuals in certain regions. This policy change created a large-scale quasi-experimental situation from which a lot can be learned about the impact of unemployment insurance rules on the dynamics of employment, unemployment, and wages. We find that the REBP led to a tremendous increase in unemployment which was due to both an increase in the inflow to and the outflow from unemployment. The REBP also induced a strong increase in early retirement and in many cases, in particular for steel workers, entering unemployment meant withdrawal from the labor force. Finally, we show that there were also non-negligible effects of extended benefits on the level and the distribution of wages.

JEL Classification: C41, J64, J65

Keywords: quasi-experiments, maximum benefit duration, unemployment inflow, duration of unemployment, early retirement, earnings, inequality.

${ }^{*}$ We are grateful to Adrian Kienast, Andreas Kuhn, and Oliver Ruf for superb research assistance and to Maria Hermann for checking the manuscript. Address: Rafael Lalive, Blümlisalpstr.10, CH-8006 Zürich, rlalive@iew.unizh.ch; Josef Zweimüller, Blümlisalpstr.10, CH-8006 Zürich, zweim@iew.unizh.ch.
\end{abstract}




\section{Introduction}

In June 1988, the Austrian government enacted, in January 1992 reformed, and in August 1993 abolished, the Regional Extended Benefit Program (REBP). This program extended the entitlement to regular unemployment benefits for elderly individuals in certain regions to a maximum of four years. These successive policy changes over time together with the discrimination by regions and by the age of the unemployed created a large-scale quasi-experimental situation from which a lot can be learned about the impact of benefit duration on labor market outcomes. The aim of this paper is to study these effects with respect to various labor market outcomes.

The REBP was enacted in response to the international steel crisis during the 1980s that hit the traditional iron and steel regions in Austria particularly hard. Thus the benefit extension was a policy response to the expectation of adverse labor market conditions. Differences in the observed labor market outcomes between the treated and non-treated individuals are therefore a mixture between a causal impact of the benefit extension on the labor market behavior of individuals and firms as well as the result of a negative shock on the labor market. The present analysis will deal with this problem in an informal way. In a companion paper (Lalive and Zweimüller, 2000) we study in detail for the case of unemployment duration how the above two effects can be separated.

The generosity of the European unemployment insurance systems is generally viewed as a candidate explanation for the cross-Atlantic differences in labor market performance. Hence, a first aim of this paper is to document the impact of the REBP on employment and unemployment levels.

We then discuss how the increase in unemployment can be split up into the unemployment inflow and the outflow. Unemployment inflow reflects to a large extent the incentives of the REBP on firms' employment decisions, unemployment outflow represents the effects of REBP on the search behavior of the workers. A possible impact of the unemployment insurance system works not only via its direct effect on the outflow from unemployment but may also significantly affect other dimensions of labor supply behavior. This paper therefore aims to take a broader look at the problem by looking at nonemployment, which represents to a large extent long-term sickness and early retirement. These latter states are of particular relevance as the increase in the benefit duration applied only to older workers and because the Austrian 
social security system handled access to disability and to early retirement benefits rather generously. With respect to possible effects of the REBP the interesting question is whether this tremendous benefit extension was effectively a policy measure that led older workers to withdraw completely from the labor market. ${ }^{1}$

The REBP may not only have created a substantial disincentive to the supply of labor but may also have a potentially significant effect on employment decisions of firms. With seniority rules characterizing the wage policies covering older workers, the REBP may have provided an incentive for firms to get rid of older high-wage workers. As the REBP constituted an improvement in the workers' outside option this may have made it easier for firms to defect on these long-term seniority contracts (Winter-Ebmer, 2002). Hence, it is interesting to see how the REBP affected employment choices of the firms.

Our data set comes from two sources. The first data source are the Austrian social security records which contains detailed information on the workers' employment and earnings history. We use a $10 \%$ sample of male employees in the Austrian private sector in the age group 40-59 and follows these individuals over the period 1984 to 1998. The second data set is the Austrian unemployment register and covers the universe of males entering unemployment between 1986 and 1995 in the age group 45-54. This inflow is then observed until 1998.

The paper is organized as follows. In section 2 we review the theoretical and empirical literature on the impact of unemployment insurance systems on the labor market. In section 3 we provide some information on the Austrian labor market, survey the Austrian unemployment insurance system, and give a detailed description of the Austrian REBP. Section 4 describes the data in more detail and gives an overview of the empirical approach we pursue. In section 5 we first present detailed evidence on effects of the REBP on the stocks of employment and unemployment and then discuss briefly the impact of the REBP on structural change in the concerned regions. Section 6 focuses on the dynamics of unemployment. We look at the in- and outflow from unemployment and consider not only transition rates to regular jobs, but put also particular emphasis on entry into early retirement. How the REBP affected the life-cycle labor force participation of various cohorts is analyzed in section 7 . Section 8 studies the impact on

\footnotetext{
${ }^{1}$ The youngest eligible worker (one who starts his unemployment spell at age 50) can draw benefits until the age of 54. The likelihood to get some form of early retirement benefits (long-term sickness, disability or early retirement pensions) is already significantly high in that age range.
} 
the earnings structure. Section 9 draws the conclusions.

\section{Theory and Previous Empirical Evidence}

Most of the previous literature that addresses the impact of the unemployment insurance system on the labor market has focused on its impact on the duration of unemployment. Important theoretical work in this area is based on job search theory (Mortensen, 1977, Burdett, 1979, Van den Berg, 1990). In these models, job seekers determine the reservation wage and the job search intensity optimally given the current labor market state and rational expectations concerning the future payoff to the relevant labor market states. According to this theory increasing generosity of unemployment insurance will lengthen the expected duration of unemployment because this raises the value of remaining unemployed relative to the value of taking up a regular job.

The empirical literature on the effects of unemployment insurance on unemployment has largely confirmed this proposition. Katz and Meyer (1990) estimate an increase in unemployment duration of .16 to .20 weeks per additional week of potential benefit duration which is close to the findings of other US studies (Moffitt and Nicholson, 1982, and Moffitt, 1985). Ham and Rea (1987) reach a somewhat larger result for Canada. Hunt (1995) and Bratberg and Vaage (2000) find a similar effect, respectively, for Germany and for Norway, whereas Winter-Ebmer (1998) finds a somewhat smaller impact for Austria. ${ }^{2}$

The theoretical literature that deals with the effects of the unemployment insurance system on the unemployment inflow can be distinguished between studies that concentrate on layoffs and studies that analyze voluntary quit behavior. The literature on layoffs has focused on implicit contracts in the face of product demand fluctuations. Imperfect experience rating leads those firms to lay off workers who will experience a less than proportionate increase in the unemployment insurance bill (Feldstein, 1976). Firms will choose to lay off workers who are covered by unemployment insurance rather than those who are not covered (Baily,

\footnotetext{
${ }^{2}$ Other recent studies that shed light on the importance of benefit eligibility compare between receivers and non-receivers of unemployment benefits (Carling et al. (1996) for Sweden and Bover et al. (1998) for Spain); or study major cuts in benefits (e.g. Carling et al. (1999) look at a major benefit cut in Sweden and Abbring et al. (1998) and Van den Berg et al. (1998) look at the impact of major benefit cuts due to sanctions in the Netherlands).
} 
1977; Jurajda, 2000). ${ }^{3}$ Workers who are entitled to unemployment insurance will have higher reservation wages than other workers and will therefore be less likely to find a suitable job with a different employer.

The theoretical prediction of unemployment insurance on quit decisions depends on the unemployment insurance system. In the US, voluntary quitters are not entitled to unemployment benefits, hence higher generosity (e.g. due to longer benefits) should decrease the quit rate. The reason is that by staying another period there is a chance to be laid off and qualify for benefits. In Austria, quitters are entitled to unemployment benefits but there is a waiting time of four weeks (see Section 3). The theoretical prediction is then less clear. More generous unemployment benefits in such a system tend to increase the likelihood of a quit as the value of unemployment increases. This has to be weighed against the negative effect mentioned above. The net effect essentially depends on the length of the waiting period.

The empirical literature on unemployment inflow has focused mainly on the US experience and is to a large extent concerned with the effects of imperfect experience rating. These effects are found to be large (Topel, 1983, 1984, 1985; Card and Levine, 1994). Topel (1985) uses a measure of the proportion of unemployment benefits subsidized by the government and shows that this measure affects unemployment inflow strongly. Andersen and Meyer (1994) find that, on the one hand, the benefit level strongly affects inflow into unemployment; on the other hand, the effect of entitlement to unemployment benefits on unemployment inflow is not significantly different from zero. In contrast, Jurajda (2001) finds that entitlement to unemployment insurance strongly affects layoffs whereas neither the benefit level nor potential duration of benefits are significant (conditional on entitlement). ${ }^{4}$ Anderson and Meyer (1997) show that the probability of unemployment take-up strongly increases in the expected level of unemployment benefits.

Baker and Rea (1998) and Christofides and McKenna (1996) analyze the effect of benefit eligibility on the hazard of ending an employment spell in Canada. They find that there is a

\footnotetext{
${ }^{3}$ Burdett and Hool (1983) and Haltiwanger (1984) generalize the implicit contracts literature by introducing bargaining and by allowing for the interaction of stock adjustment and factor utilization decisions.

${ }^{4}$ The two studies differ in terms of the statistical analysis. Whereas Jurajda estimates a multivariate mixed proportional hazard model to account for duration dependence and correlated unobserved heterogeneity, Anderson and Meyer (1994) focus on quarterly employment probabilities. For further differences, see Jurajda (2001).
} 
positive spike in the week when individuals become entitled to unemployment benefits. Nickell (1982) analyzes time-series of flows into unemployment in Britain and finds no evidence of the effect of the level of unemployment benefits. Winter-Ebmer (2002) analyzes the Austrian REBP and finds that extended benefits increased the yearly inflow into unemployment by at least 3 percentage points per year.

The impact of unemployment insurance on labor market dynamics and the level of wages is studied in matching models (Pissarides, 2000). The prediction is that unemployment insurance strengthens the bargaining position of workers thus leading to higher wages. However, wages do not increase one-for-one with unemployment benefits because higher wage pressure reduces profits leading to lower job creation (with fixed job productivity). This result holds with endogenous job destruction (Mortensen and Pissarides, 1994) and match heterogeneity (Marimon and Zilibotti, 1999). The bulk of the matching literature assumes risk neutrality of the workers. Acemoglu and Shimer (1999) analyze the optimality of unemployment insurance in a model with risk-averse workers and investment on the part of firms in capital-intensive high-wage jobs. They show that the optimal unemployment insurance is characterized by high wages because generous unemployment insurance raises the incentives for firms to create capital-intensive jobs. While the theoretical literature on this issue is extensive (for a survey see Mortensen and Pissarides, 1999), the empirical literature on the effects of unemployment insurance on wages is sparse. Acemoglu (1997) finds a large effect of unemployment insurance on the capital intensity of jobs across states in the US. ${ }^{5}$ The literature concerned with structural estimation of job search models established the positive effect of unemployment insurance on the reservation wage (see Wolpin, 1995, for a survey).

There are two previous studies analyzing the impact of the Austrian REBP. Winter-Ebmer (1998) who looks at the initial impact of the benefit extension on unemployment duration at the period of introduction of the REBP. He finds that the benefit extension decreased the job hazard rate by somewhat less than $20 \%$. The second paper, Winter-Ebmer (2002), studies the impact on the inflow into unemployment and finds substantial REBP-effects also on unemployment entry. The conclusion is that the increase in unemployment entry was most

\footnotetext{
${ }^{5}$ Anderson and Meyer (2000) address the related but different question of how unemployment insurance taxes are shifted to workers when the system of unemployment insurance financing is changed from a flat unemployment insurance tax to experience rating.
} 
likely due to layoffs of high-tenured and older workers rather than voluntary quits.

The present paper goes beyond this study in at least five important respects. First, we consider not only the impact of the benefit extension after its introduction, but also the impact of the reform and of the abolishment of the REBP. Secondly, we use a more informative and much larger data set. This allows us to focus on a narrow age group and avoid a possible bias resulting from a misspecification of the effect of age. Thirdly, we put particular emphasis not only on the transitions between employment and unemployment, but we also look the problem of early retirement (including long-term sickness and disability pensions). This is of particular importance as access to early retirement was generous during the period under consideration. Fourthly, we put particular emphasis on a distinction between steel workers and employees in other industries. This allows us to highlight in a rather informal way the relative importance of labor market conditions (which were very severe for the former group) and causal effects of benefit entitlement rules (which may be a more dominant factor for labor market behavior for workers in other industries). Finally, we also look at the question whether wage formation was affected by the change in the benefit system. As the program affected a large fraction of the male working population such effects could well show up. We will look both at median wages and the wage spread between high- and low wage workers.

\section{The Austrian Unemployment Insurance System}

Austria has been a country with a low unemployment rate and a low average duration of unemployment, as measured by European standards. In 1994, the overall unemployment rate was $6.8 \%$ and the percentage long-term unemployed ( $\geq 12$ months) was less than $20 \%$, which is much closer to the US figures than to the European average.

Table 1

While Austria has been doing relatively well in terms of unemployment outcomes, the unemployment situation of workers above age 50 has deteriorated dramatically over the period 1988 to 1993 . The unemployment rate of the age group 50-59 was $5.1 \%$ in 1988, which was even below the 1988 overall unemployment rate of $5.3 \%$, but it doubled until 1993 when it increased above $10 \%$ (see Table 1). Figure 1 shows that there was a steady increase in the ratio of the unemployment rate of the age group 50-59, relative to the age group 40-49, a trend 
which did not stop until 1993, when the law was abolished. Figure 1 also shows that this increase in the relative unemployment rate was almost exactly matched by an increase in the relative incidence of long-term unemployment. The former ratio increased from 1.11 in 1988 to 1.67 in 1998 whereas the latter increased from 1.37 in 1988 to 2.09 in $1993 .^{6}$

\section{Figure 1}

The Austrian unemployment insurance system distinguishes two types of unemployment compensation: (i) regular unemployment benefits ("Arbeitslosengeld", UB) and (ii) unemployment assistance ("Notstandshilfe", UA). Until August 1989 UB-benefit duration was 30 weeks provided that the unemployed had paid unemployment insurance contributions for at least 156 weeks within the last 5 years prior to the current spell. These rules were changed in August 1989 and UB-duration became dependent not only on previous experience but also on age. Benefit duration for the age group 40-49 was increased to 39 weeks if the job seeker has been employed 312 weeks of employment within the last 10 years prior to the current spell. For the age group 50 and older, UB-duration was increased to 52 weeks if the unemployed has been employed for at least 468 weeks within the last 15 years.

Voluntary quitters and workers discharged for misconduct can claim benefits not until a waiting period of 4 weeks has passed. Both UB and UA recipients are expected to search actively for a new job which should be within the scope of the claimant's qualifications, at least during the first months of the unemployment spell. Non-compliance with the eligibility rules is subject to benefit sanctions that can lead to withdrawal benefits for up to 4 weeks.

Once unemployment benefits have run out, the unemployed individual can apply for unemployment assistance. Austrian citizens and foreign workers with a long-term work-permit are eligible to UA which is granted for successive periods of at most 39 weeks, after which entitlement can be renewed. There is no limit for the number of such renewals, so the UA-duration is basically infinite.

Compared to other European countries, the replacement ratio (UB relative to gross monthly earnings) is rather low and depends on previous earnings. In 1990 the replacement ratio was $40.4 \%$ for the median income earner; $48.2 \%$ for a low-wage worker who earned half the median;

\footnotetext{
${ }^{6}$ In 1988, the fraction of individuals in the unemployment stock who were unemployed for at least a year was $18.6 \%$ among in the age group 40-49, and $22.9 \%$ in the age group 50-59. In 1993, the corresponding figures were $17.8 \%$ and $37.2 \%$.
} 
and $29.6 \%$ for a high-wage worker earning twice the median income. On top of this, family allowances are paid. UB are not taxed and not means-tested. UA is means tested and depends on the income and wealth situation of other family members and close relatives. UA payments are lower than UB and amount to at most $92 \%$ of UB. In 1990, UA was on average $78 \%$ of UB as a result of the means test. In 1990, the majority of the unemployed (59\%) received UB and $26 \%$ received UA.

\subsection{The Regional Extended Benefit Program (REBP)}

In June 1988, the Austrian government enacted a law that extended UB-entitlement to 209 weeks for a specific subgroup. This group consisted of individuals considered to suffer most heavily from the adverse labor market consequences of the international steel crisis. The crisis hit certain regions of the Austrian economy, in particular regions where state-owned firms were located. Moreover, the measure intended to help also employees in other industries that were indirectly affected by the crisis and the restructuring process that was initiated in many nationalized firms thereafter (Hesoun, 1988).

An unemployed worker became eligible to 209 weeks of UB if he or she satisfied each of the following criteria:

(i) age 50 or older,

(ii) a continuous work history (780 employment weeks during the last 25 years prior to the current unemployment spell),

(iii) location of residence in one of 28 selected labor market districts since at least 6 months prior to the claim,

(iv) new unemployment spell after June 1998 or spell in progress in June 1988.

The REBP was in effect until December 1991 when a reform of these rules took place which came into effect in January 1992. This 1991-reform left all claims in progress unaffected. Only new claims were subject to the new rules.

The 1991-reform included two important changes. First, the reform abolished the benefit extension in 6 of the original 28 regions. The program ended in December 1991 in these districts because the respective labor markets were considered to have improved significantly so that the long UB-entitlement was no longer justified.

The second important change with the 1991-reform was a tightening of the eligibility cri- 
teria to extended benefits: new beneficiaries had to be not only residents, but also previously employed in one of the (now only 22) specified regions. The location of the previous employer as an additional eligibility requirement has a quantitatively important impact on the potential number of beneficiaries because a substantial number of residents in REBP-regions were working in a labor market district not covered by the benefit extension.

It is important to emphasize that all individuals in the sample that will be analyzed in Section 6 are potentially eligible to unemployment assistance transfers. We cannot observe the level of UA since information on the income and wealth situation of family members and close relatives is not available in our data. A possible impact of extended benefits is therefore due to the more generous UB relative to UA; to reductions in UA due to the means test; and to the negative connotation of a 'welfare recipient' associated with the UA-status.

\section{Data and Method}

Our data set comes from two sources. The first data source are the Austrian social security records which contains detailed information on the workers' employment and earnings history. Our particular data set contains a $10 \%$ sample of male employees in the Austrian private sector, covers all workers in the age group 40-59, and follows these individuals over the period 1984 to 1998 . There is a period of approximately $41 / 2$ years (January 1984 to June 1988) before the REBP was introduced; a period of about 5 years (June 1988 to July 1993) when the benefit extension was in effect, and a further period of 5 1/2 years (August 1993 to December 1998) after this law was abolished. The second data source is the Austrian unemployment register. We consider the universe of male unemployment entrants in Austria in the age group 45-54 over the period 1986 to 1995 and follow these individuals up to end of the year 1998.

The main focus of our analysis will be on a comparison between the age group 45-49 and 50-54. As we can assume that workers in this age group are close substitutes our estimates cannot be strongly affected by a direct effect of age. This is of particular importance since age is an eligibility criterion for the REBP. On the other hand, these two groups may be 'too close' substitutes in the sense that e.g. a strong reduction in employment for the age group 50-54 may feed back to the labor demand for age group 45-49 via general equilibrium effects. It will therefore be instructive to also consider age groups that are further away from the critical eligibility age 50. Moreover, a broader age window also allows us to look at life cycle effects and 
look at possible persistence effects of the REBP on labor market outcomes after the program has been abolished.

We present the results of our analysis in four steps. We first concentrate on the levels of employment, unemployment, and non-employment (predominantly some sort of early retirement); as one important motivation for the introduction of the REBP was to facilitate structural change (downsizing of the steel industry that came in severe troubles with the international steel crises in the mid 1980s), we will also look to which extent the structure of employment has change in REBP-regions relative to other regions.

This analysis clearly shows that unemployment levels are dramatically higher in those regions where the REBP was imposed. Higher levels of unemployment, of course, can either be the result of higher unemployment risk given the average duration of an unemployment spell; or a higher duration, given the risk of unemployment; or both. The second step of our analysis is therefore to look at the dynamics of unemployment and to see to which extent this higher unemployment levels have increased not only the average duration of an unemployment spell but also the inflow rate.

Job search theory holds that the variable that should be directly affected from an extension of unemployment benefits is the expected duration of job search. So the most interesting question is how the outflow from unemployment has been different between unemployment entrants that were eligible to the REBP relative to those who were not. An important aspect in this evaluation is the question whether a longer duration of unemployment for REBP-eligible workers is due to a causal impact of extended benefits, and to which extent this is simply the results of worse labor market conditions for these individuals, the latter fact being the reason why the REBP was introduced in the first place. This means the REBP was an endogenous policy response due to the expectation of worse labor market conditions in those regions. A companion paper (Lalive and Zweimüller 2000) analyzes this question in detail. Here we will give some informal evidence about the possible size of the bias that arises when this endogenous policy adoption is not accounted for.

It is very likely that the REBP has had not only an important impact on the duration of unemployment but also on the risk of unemployment. We will therefore look at the unemployment inflow. The aim of the REBP was not only to insure older workers against worse job chance in case they suffer an unemployment spell, but also to facilitate downsizing of struc- 
turally weak (in particular, iron and steel) industries that were concentrated in those regions. This meant that the typical workers did face a higher risk of unemployment. It is therefore interesting to see whether the inflow into unemployment of older workers in these regions is significantly concentrated in those periods and regions where the REBP was in effect. The idea is that, by improving the workers' outside options, the REBP decreased the firing costs of firms and allowed firms to defect on long-term seniority contracts.

The third dimension we are interested in are life-cycle aspects. How did the introduction of the REBP affect labor supply behavior of various cohorts? Since we are concerned with a program that helps older workers, the interesting question is how this program affected the transition process of these workers from labor force participation to retirement. We will contrast the experience of those workers who were never entitled to the REBP to cohorts that were partly and/or entirely eligible to the program.

The final variable which is analyzed in this study and which may have been potentially affected by the REBP is the structure of wages. We look at older workers' wages at the 3rd, 5th, and 7th decile of the wage distribution and look at the differences between workers eligible to the REBP relative to the wages of those groups that were never eligible to that program. Also with respect to wages it is interesting to contrast wages of currently employed individuals (= the employment stock) and the relative wages of destroyed and new created jobs (= employment flows).

\section{The Impact of the REBP on the Levels of Employment and Unemployment}

Figures 2 and 3 show how, for the age groups that were affected by REBP, the employment rate and the unemployment rate developed over the period 1984 to 1998. Note that the denominator of the ratio shown in these Figures includes the whole population in that age group so the numbers in Figure 2 are therefore comparable to the employment population ratio, whereas the numbers in Figure 3 are the unemployment population ratio and not comparable to the unemployment rate, as it usually measured (unemployed relative to employed plus unemployed). To avoid confusion we will refer to these measures as, respectively, the employment ratio and the unemployment ratio. 
Figure 2

Figure 2 compares the employment ratios for elderly workers in REBP-regions to those in non-eligible regions, separately for workers in the age group 50-54 and for workers aged 55-59. Consider first the age group 50-54. For this group there is almost no regional difference in employment performance before the REBP starts: about 90 percent of all workers observed in our sample are employed in 1984. In 1988, the period when the program started, the two indicators start to diverge and the employment ratio of workers in REBP-regions falls behind the one of the non-eligible group. The difference increases and reaches its maximum in 1993, the year when the REBP was abolished. The regional difference in employment ratios in that period is very large and amounts to almost 10 percentage points. After the abolishment of the program, the employment ratio in REBP-regions increases again and reaches the level of the non-treated regions in 1998. Note also the overall downward trend in the employment ratio over the whole period shown in the upper panel of Figure 2: starting from a level of $90 \%$ in the mid 1980s, the employment ratio has come down to $80 \%$ by the end of the 1990s.

The employment situation is different for the age group 55-59. For these older workers there is a significant regional difference in the employment ratio already before the REBP was introduced; moreover, in the treated regions this ratio decreases strongly until 1988 when the REBP-start, stays at a very low level during the REBP-period and increases slightly thereafter. In contrast, the employment ratio follows a smooth downward trend in the control regions. Note that in the age group 55-59 the overall downward trend over the period under consideration is even stronger than for the age group 50-54. In the mid 1980s the employment ratio in control regions was almost $80 \%$, and by the end of the 1990 s this ratio has come down to less than $60 \%$.

Figure 3

Figure 3 shows the corresponding picture for the unemployment ratios. For both age groups we see the same picture. Slightly lower unemployment ratios in the REBP-regions before the program starts; an increase during the REBP-period, and a decrease of the ratio after the program had been abolished. By the end of the 1990s the unemployment ratio in REBPregions has fallen below the one of control regions for both age groups. Note also that the differences in unemployment ratios are tremendous: for the age group 50-54, this difference 
becomes as large as 7 percentage points (in year 1992); for the age group 55-59 the difference becomes even higher (11 percentage points in 1993). (Note that differences in conventionally measured unemployment rates would be even higher).

Two further points that emerge from Figures 2 and 3 are worth mentioning. The first point concerns the long-term effects of the REBP on employment and unemployment. In both Figures we see significant differences between treated and non-treated regions even after the program has been abolished. This is not surprising given the fact that unemployment entrants in REBP-regions in 1993 (when the program ends) are still entitled to draw benefits until the year 1997. So we should actually see differences in our labor market indicators until that period. Interestingly, exactly this picture shows up in Figures 1 and 2 (the only exception being the employment ratio for the age group 55-59).

The second interesting point refers to nonemployment (=individuals neither employed nor unemployed). While for the age group 50-54 there are no dramatic regional differences in the fraction of individuals that have completely withdrawn from the labor force throughout the considered period, these differences become large for the age group 55-59. Figure 3 shows that, in this age group, there are very strong regional differences in the fraction of individuals that have withdrawn from the labor market. But the highest difference already occurred at the date when the REBP was introduced and starts to decrease thereafter. Figure 3 suggests that a sizeable fraction of those who otherwise would have been nonemployed, became eligible to extended benefits. This increases unemployment and reduces nonemployment. Nevertheless, it is obvious from Figure 4 that nonemployment remains much higher in REBP-regions also during and after the program.

\section{Figure 4}

Figures 2 to 4 all refer to workers older than 50. A comparison of the regional difference in employment and unemployment ratios for workers under 50 is informative. If we would see the same picture as in Figures 2 and 3 also for workers under 50, the obvious interpretation would be that adverse labor market shocks, specific to the time-period 1988-1993 and to the REBPregions - but not the increase in benefit entitlement in these regions - account for the empirical evidence. Only if there is a significant difference in labor market performance between workers above and below age 50 we can causally link the large regional differences shown in Figures 2 and 3 to the increase in benefit duration provided by the REBP. 
Figure 5

Figure 5 clearly shows that, for workers below age 50 , the regional differences between treated and non-treated regions are small in comparison to the regional differences for workers aged 50 and older. In fact, (un)employment performance of workers below 50 is even slightly better in REBP-regions, both for the age group 40-44 and the age group 45-49. Differences in non-employment ratios are negligible Figure 4 therefore clearly suggests that, in treated regions, workers above age 50 do not do worse because of worse labor market conditions in these regions during the program. There appears to be causal link between the benefit extension and the employment performance of the concerned individuals.

In sum, a very clear picture emerges: for eligible workers, both unemployment and employment ratios are rather equal between the two regions before the program starts; during the treatment period the employment ratio and the unemployment ratio strongly increase, reach a turning point around the year 1993, and decrease thereafter. The REBP-effect is long-lasting: employment and unemployment levels in treated regions remain significantly higher even after 1993 and reach the corresponding levels of the non-treated regions not until the year 1998. No such pattern is observed for non-eligible workers. We are therefore lead to conclude that there is a causal link from the entitlement to long benefits to employment performance.

As mentioned above the REBP was introduced in reaction to the international steel crises in the mid 1980s. Regions covered by the program had typically a high percentage of workers employment in the iron and steel industry. The REBP did not only help older workers in case of unemployment but was also an indirect subsidy to employers as it allowed firms to get rid of older employees in overstaffed plants more easily. It is interesting to see to which extent this has changed the structure of employment in these regions relative to the rest of the economy.

Table 2

Table 2 shows the fraction of steel workers in total employment at the period when the REBP started (1988), immediately before the reform of the program (1991), and when it was abolished (1993). Among the age group above 55 the percentage of steel workers is already low, meaning that early retirement is prevalent for workers in these industries and it was so already before the program started. For the age group 50-54, however, the reduction is dramatic. During the REBP-period, there is a continuous fall in employment in the steel industry, the 
fraction of workers aged 50-54 falls from almost $20 \%$ in 1988 to less than $12 \%$ in 1993 . We see also a reduction in steel-industry employment shares for younger workers, but the fall for these groups is only half as large. It is clear from Table 2 that there is no such trend in the non-treated regions. In these regions the employment share of iron and steel industries stays at around $4 \%$, with no dramatic difference across age groups and time.

\section{Unemployment Dynamics and the REBP}

The higher level of unemployment during the REBP-period may either be due to a longer average duration of unemployment for eligible workers; or it may be due to an increase in the unemployment inflow. As mentioned above, it is very likely that the REBP did not only lead to longer unemployment spells, but also to an increased inflow into unemployment, since the REBP provided a chance for firms to fire older workers at comparably low cost. We now proceed by looking at these two channels separately.

\subsection{The REBP and the Increase in Unemployment Duration}

Table 3 gives information about the unemployment spells in treated and non-treated regions. In total, 385,463 unemployment spells were started by males in the age group 45 to 54 during the period 1986 to 1995 . The upper panel shows the survivor rates for these spells, separately for workers eligible to the REBP and for non-eligible workers. The message of Table 3 is clear: unemployment spells suffered by individuals eligible to the REBP last longer. For these individuals, more than $30 \%$ of all spells are still in progress after one year, as opposed to only $9 \%$ for individuals that are not eligible. ${ }^{7}$ On average, a treated spell lasts about 10 months and is about 2.5 times as long as a non-treated one. Note that this number refers to completed durations. The fraction of treated spells that is still in progress by the end of our observation period (December 1998) amounts to almost $8 \%$. Treated spells were started before August 1993, which means that the elapsed duration of a treated spell that is censored is at least 5 $1 / 2$ years.

\footnotetext{
${ }^{7}$ Note that these numbers are drawn from an inflow rather than a stock sample (to which offical numbers on the percentage long-term unemployment usually refer). Clearly, the fraction of long-term unemployed at an arbitrary point of time is larger than $10 \%$ due to the well-known oversampling of long-term spells in stocksamples.
} 
Table 3

Both for treated and non-treated spells, by far the most important exit status is employment. In total, three out of four unemployment spells end in a regular job, the remaining spells are followed by a spell of non-employment, predominantly long-term sickness ${ }^{8}$ or some form of early retirement. The differences between spells eligible to the REBP and those that are not is large: among the former, only $55.5 \%$ among the eligible individuals return to a job; and almost $25 \%$ of eligible spells (but only $10 \%$ of the non-eligible ones) end either in long-term sickness or early retirement. A sizeable fraction of individuals exit to non-employment for reasons that cannot be observed in the data. There are no important differences between treated and non-treated spells along this dimension.

An open question is whether the extreme differences by eligibility to the REBP represents a causal relationship that goes from the extension in benefits to the duration of unemployment or whether this is a statistical artifact simply arising from adverse (regional and age-specific) labor market shocks in the REBP-regions. In order to investigate this question informally, we show two pieces of evidence. ${ }^{9}$ The first is a separate analysis of the experience for steel and non-steel workers (Table 4). Adverse labor market conditions should predominantly be observed in the former group. Secondly, we report an analysis that distinguishes between REBP-regions that had labor market conditions which were comparable to the control regions and those which had particularly strong labor market problems (Table 5). A comparison of non-eligible spells with those treated spells in the former regions should entirely reflect a causal impact of the REBP. ${ }^{10}$

\section{Table 4}

\footnotetext{
${ }^{8}$ In accordance with the literature, long-term sickness is defined as a sickness spell that lasts longer than 3 months. Unemployment spells that are interrupted by short-term sickness spells are lumped together. This is in line with UB-eligibility rules. During sickness the claim is interrupted, and can be used up after the sickness spell ends.

${ }^{9}$ For a detailed econometric analysis of this problem, see Lalive and Zweimüller (2000). The results in this paper suggest that half of the difference in unemployment duration between treated and non-treated individuals is due to the increase in benefit duration.

${ }^{10}$ For a paper that analyzes causal effects of extended benefits on exits to employment with a similar empirical strategy, see the study of Card and Levine (2002).
} 
Table 4 shows that steel workers are longer unemployed and have a lower probability to return to employment than non-steel workers. This is shown by all comparisons presented in Table 5, but among treated spells these differences are strongest. Only one third of REBPeligible steel workers that enter an unemployment spell again find a regular job. Note that this number is not flawed by right-censoring. Right-censored, treated spells last at least $51 / 2$ years, the likelihood that these workers will find a regular job is certainly close to zero. In sum, the evidence for steel workers shows that the worse unemployment experience for eligible workers must, to a non-negligible degree, be due to a bad labor market.

To see more closely possible causal effects of the benefit extension on unemployment durations, it is instructive to compare the experience of unemployed individuals that face similar labor market conditions. The REBP provides an interesting natural experiment in this respect. The 1991 reform of the program, that came into effect in January 1992, excluded several districts that were eligible during the period 1988-1991. The reason was that labor market conditions were found to have significantly improved, so REBP-eligibility was no longer justified. In fact, it can be argued (see Lalive and Zweimüller, 2000) that it turned out ex post that labor market conditions in these regions were rather similar to control regions already during the pre-reform REBP-period. A comparison of these regions to control regions should therefore not be biased by differences in regional labor market performance. Hence, observed differences between treated and non-treated spells are most likely the consequence of differences in benefit duration rules.

\section{Table 5}

Table 5 distinguishes unemployment duration outcomes of treated individuals in the set of regions that was excluded in the reform of January 1992 (treated, TR1), treated individuals in the remaining regions (treated, TR2), and job seekers who were never eligible to extended benefits. Comparing unemployment duration outcomes of the job seekers in TR1 with the nontreated individuals gives an upper bound of the effect of extended benefits on unemployment duration. ${ }^{11}$ Clearly, extended benefits increase mean completed duration by about 7 weeks. Moreover, extended benefits do not appear to reduce labor force participation as indicated by the small difference in exits to a regular job. A comparison of treated individuals in TR1 to

\footnotetext{
${ }^{11}$ Recall that treated workers are on average older than non-treated workers.
} 
job seekers in TR2 allows assessing the size of the policy endogeneity bias, the extent to which the effects of extended benefits may be overestimated due to adverse labor market shocks in the set of TR2 regions. The effect of extended benefits on mean completed duration is about 29 weeks - more than four times the aforementioned estimate. Moreover, in the set of TR2 regions, REBP appears to decrease labor force participation tremendously. The percentage of individuals who is ever observed to start a regular job is 25 percentage points lower for treated workers in TR2 than for non-treated workers.

\subsection{Did the REBP Increase the Unemployment Risk of Older Workers?}

The generous entitlement to regular unemployment benefits provided by the REBP represent a decrease in firing costs for older workers. Did this result in a higher risk of unemployment for the eligible group? Figure 6 gives an answer to this question. The numbers in Figure 6 are the quarterly inflow rate, from May 10 th to August 10th of each year, ${ }^{12}$ and refer to the age groups 50-54 (upper panel) and 55-59 (lower panel).

Figure 6

For both age groups there are no particular regional differences in the inflow rates from employment to unemployment in the mid 1980s. For the age group 50-54 this picture changes in 1988 when the REBP was introduced; and already somewhat earlier for the age group 5559. Moreover, the observed regional differences are large: on average, the inflow rates of the treated group are about twice as large as the inflow rates of non-eligible workers.

Moreover, there is an interesting pattern as far as the timing of these inflows is concerned. For both age groups the inflow rate for workers eligible to the REBP reaches a peak in the years 1991 and in 1993: a time pattern that is not visible for the non-entitled workers. The years 1991 and 1993 are, respectively, the periods immediately before the reform and the abolishment of the REBP. The reason why the inflow rates are higher during these periods can easily be rationalized by an 'end-game' situation between firms and workers: firms who have to downsize their work force for structural reasons will find it easier to convince worker representatives to lay off workers in a period when the individual costs of unemployment are still comparably low.

\footnotetext{
${ }^{12}$ We do not display the remaining quarters. There is a strong seasonal pattern in these series, and in the third quarter unemployment entry is of low importance due to seasonality.
} 
The expectation of a strong increase in these costs due to a shorter duration of unemployment benefits facilitates an agreement with high layoffs now and low layoffs later (when the extended benefits program has run out). The same pattern shows up not only for the year 1991 and the year 1993 but also for both age groups 50-54 and 55-59.

Figure 7 shows the regional differences in unemployment inflow rates for the younger age groups 40-44 and 45-49. It is evident from this figure that these differences are not particularly high and there are no time patterns comparable to those observed for the workers above age 50. However, it is interesting to see that, with only a few exceptions, inflow rates for younger workers are somewhat smaller in the treated regions over the entire period. This is consistent with the proposition that the REBP has improved the employment prospects of younger workers in treated regions via general equilibrium effects: The REBP increased the demand for workers below 50 relative to workers above 50 in these regions. Where a employment reductions became necessary, and this has taken the form of firing the older workers but keeping the somewhat younger, closely substitutable employees.

\section{Figure 7}

The REBP was a reaction to a shock that did not only hit a particular region, but also one that hit a particular sector: the steel industry. It is therefore interesting to see whether the unemployment inflow rates were different by sectors. Figure 8 shows that there is very strong difference between the unemployment risk of steel-workers (lower panel) and employees in other industries (upper panel). While also in the non-steel industry inflow rates for older workers in REBP-regions are higher, the regional difference is comparably small. For the steel industry, the differences are tremendous: in 1993 the quarterly inflow rate amounts to as much as $15 \%$ for workers aged 50-54 and about $5 \%$ for workers aged 55-59. Interestingly, the above mentioned time pattern - peaks in the inflow rate in the years 1991 and 1993 - are observed for all groups in Figure 8.

Figure 8

Figure 8 suggests an interesting point. REBP-regions were regions that were hit particularly hard by the international steel crises in the 1980s. The REBP transmitted this sectoral/regional shock into an age-specific shock. Firms who had to decrease their employment levels fired 
workers that had access to generous transfer payment from the government. What we see for steel workers in Figure 8 can therefore not be interpreted as a causal impact of benefit duration on the unemployment inflow rate, but rather as the consequence of a very bad labor market situation. The impact of the REBP was to concentrate the worse labor market outcomes on the older steel workers. It is much more plausible to interpret the effect for employees in the nonsteel sectors as an upper bound for a causal impact of benefit duration on the unemployment inflow. In REBP-regions these sectors were in a shape similar to the rest of the economy but may have been hit by stronger indirect effects than the rest of the economy.

\section{REBP-Effects from a Life-Cycle Perspective}

Was the REBP a program that mainly facilitated a smooth transition from work to retirement for elderly workers? In order to look at this question, we take a more long-term perspective and look at the dynamics of labor force participation of certain cohorts. Figure 9 shows, over the period 1984 to 1998, the unemployment ratio, the employment ratio, and the labor force participation ratio for the cohorts born, respectively, in 1938, 1941, and 1944. The graphs are drawn separately for treated and non-treated regions. The cohort 1938 (age 50 in 1988) was eligible to long benefits throughout the REBP-period, the cohort 1944 was never eligible (age 50 in 1994), whereas the cohort 1941 (age 50 in 1991) was eligible only in the years 1991 to 1993. (A dotted line in Figure 9 means that the cohort is below age 50).

Figure 9

First of all, Figure 9 shows that unemployment ratio for the cohort 1938 increases during the REBP-period, stays high also after the REBP has been abolished and falls to lower levels not until the period 1998. The labor force participation ratio starts to decrease strongly after the age 54 (in 1993). Only $76 \%$ of individuals of the cohort 1938 are still at work at that age. In comparison, the corresponding fraction in the control regions amounts to $85 \%$. The difference is similar for the cohort 1941. At age 54 (year 1995, when the program was abolished, but the long-term effects of the REBP are still at work), in treated regions only $72 \%$ of the observed population aged 54 are still employed, whereas the corresponding number for the non-treated regions amounts to $82 \%$. 
No such difference is given for the cohort 1944. This cohort was never eligible to the REBP and neither the labor force participation ratio, the employment ratio, nor the unemployment ratio show any particular difference between treated and non-treated regions. Figure 9 therefore strongly supports the proposition that a main effect of the REBP was to open the door to retirement for workers that were dismissed from their jobs, even if they were still relatively young.

\section{Did the REBP Affect the Wage Structure?}

The final question concerns the level and distribution of wages and how this was changed by the REBP. One reason for the introduction of the REBP was to reduce the firing costs for overstaffed firms and allow these employers to lay off older workers that were expensive and were paid above their productivity. Did this actually happen in practice?

Table 6 gives a tentative answer to this question. We compare the previous earnings of unemployment entrants entitled to the REBP to the previous earnings of non-eligible entrants. We perform a difference-in-difference-in-difference (DiDiD) analysis that makes use of the fact that there are three criteria that determine eligibility to the extended benefit program: age, region, and time. From Table 6 we see that previous wages of unemployment entrants aged 50-54 were rather similar between treated and control regions before the program came into effect. The median of the log daily wage distribution was 6.566 in treated and 6.603 in nontreated regions. This amounts to a wage-differential of -.036. In the period during which the program was in force, previous wages of unemployment entrants were higher than before, the regional wage differential for the age group 50-54 amounted to +.105 . And this differential returned to -.029 which is very close to the pre-program situation.

Table 6

Did something similar happen in the age group 45-49? The answer is no. Throughout all three periods, unemployment entrants in treated regions had earned somewhat less than their colleagues in the control regions and the wage differential was surprisingly stable throughout the whole period. The differential amounted to -.024, -.031, and -.036, respectively before, during, and after the REBP. The DiDiD estimate for the wage gap between eligible and noneligible workers was +.149 if one compares the pre-program with the during-program situation. 
And the gap was -.129 if one compares the during-program with the post-program situation. This effect seems to be robust and estimated with a rather low standard error. The DiDiDestimator therefore suggests that unemployment entrants eligible to the REBP were older high-wage workers.

Table 7

How did the REBP affect other dimensions of the wage structure? The first row in Table 7 shows the DiDiD-estimate for unemployment entrants when not only the median but also the spread (7th/3rd decile) of the log daily wage distribution is analyzed. The result is that, just like for the median, the spread in the distribution of previous wages is larger for eligible entrants and that this effect is of a comparable size as the effect on median log wages. The final row of Table 7 addresses the question of whether extended benefits affected the distribution of accepted wages. Here we do not see any significant difference in accepted wages between treated and non-treated unemployed individuals. Hence, a longer duration of benefits appears not lead to increasing choosiness of the workers. Similarly, we do not see a clear picture on the spread of the distribution of accepted wages.

The final piece of evidence which we present here concerns the median log daily wage of all the employed individuals. Here we compare the distribution of log daily wages of the entire male labor force. The REBP seems to have lowered wages for the employed individuals in these regions by between 1 and 3 percentage points. The effect is originally small in the period during which the REBP was in effect, and becomes larger in the post-program period, and the effect is between 1 and 3 percentage points. The long-lasting effect of the REBP on wages may well reflect the wage pressure resulting from the long-lasting effects of the REBP on unemployment levels (see Figure 3). While REBP had a negative effect on the wage level, it increased wage inequality. The 7 th/3rd decile log wage differential increase both in the period when the program was introduced and in the post-REBP-period.

\section{Conclusions}

This paper has analyzed the impact of benefit duration on various dimensions of the labor market. The basis of our empirical analysis was the quasi-experimental situation that was created by the introduction of the Austrian regional extended benefit program, which granted 
four years of regular unemployment benefits to workers above age 50 in certain regions. Our empirical analysis is based on two unique and very large data sets that cover, respectively, 10 $\%$ of all male employees aged 40-59 over the period 1984-1998, and the universe of all male unemployment entrants in Austria aged 45-54 over the period 1986 to 1995.

A first main message of our analysis is that the REBP has a profound impact on the labor markets of treated regions. This means that the dominant focus in the literature, namely the impact of the unemployment insurance system on the duration of unemployment is too narrow. Important effects may also come from transitions in and out of the labor force, in the case of older workers, the important transitions are exits from employment/unemployment to some form of early retirement.

The second main message from our analysis is that a drastic increase in benefit entitlement rules may have quantitatively very strong effects. The consequence of the drastic increase in benefit duration was a dramatic increase in the levels of unemployment. The unemployment level in the treated regions was highest in the year when the program was abolished when more than $12 \%$ of the population aged 50-59 were unemployed.

The increase in unemployment was not only due to an increase in the duration, but also due to an increase in the unemployment inflow. The increase in the risk to become unemployed was particularly dramatic for steel workers, and less so for the remaining sectors of the economy. For all sectors, however, we see an interesting time pattern in the inflow. Immediately before the program ends there is a very strong increase in the inflow. This 'last minute' effect is also visible immediately before the 1991 reform.

The third main message of our analysis is that benefit extension for older workers significantly affect the life-cycle pattern of labor force participation. The long benefit duration lead to a situation where, in many cases, the start of an unemployment spell was the beginning of retirement. In other words, the benefit extension was a hidden form of early retirement. This was especially so for steel workers: one out of three unemployment spells suffered by steel workers ended in a new job. For the remaining spells of steel workers retirement had already begun.

The final message of our analysis is that the wage effects of extended benefit programs should not be neglected. For the Austrian REBP we find that predominantly high-wage jobs were destroyed as a consequence of the REBP. Moreover, the high unemployment rates that 
the benefit extension created may have affected the process of wage formation. We find that REBP-regions experienced lower wage increases than the rest of the economy, and that the spread in the wage distribution has increased. 


\section{References}

[1] Abbring, J., Van den Berg, G. and Van Ours, J. C. (1998), The Effect of Unemployment Insurance Sanctions on the Transition Rate from Unemployment to Employment, Working Paper, Tinbergen Institute, Amsterdam.

[2] Acemoglu, D. (1997), Good Jobs versus Bad Jobs: Theory and Some Empirical Evidence, mimeo, MIT.

[3] Acemoglu, D. and Shimer, R. (1999), Efficient Unemployment Insurance, Journal of Political Economy 107, 893-928.

[4] Anderson, P. M. and Meyer, B. D. (1994). The Effects of Unemployment Insurance Taxes and Benefits on Layoffs Using Firm and Individual Data, NBER Working Paper No. 4960.

[5] Anderson, P. M. and Meyer, B. D. (1997), Unemployment Insurance Benefits and Takeup Rates, Quarterly Journal of Economics 112, 913-938.

[6] Anderson, P. M. and Meyer, B. D. (2000), Using a Natural Experiment to Estimate the Effects of the Unemployment Insurance Payroll Tax on Wages, Employment, Claims, and Denials, Journal of Public Economics 78, 81-106.

[7] Atkinson, A. B. and Micklewright, J. (1991), Unemployment Compensation and Labor Market Transitions: A Critical Review, Journal of Economic Literature 29, 1679-1727.

[8] Baily, M. N. (1977), On the Theory of Layoffs and Unemployment, Econometrica 45, 1043-1063.

[9] Baker, M. and Rea, S. A. (1998), Employment Spells and Unemployment Insurance Eligibility Requirements, Review of Economics and Statistics 80, 80-94.

[10] Bratberg, E. and Vaage, K. (2000), Spell Durations with Long Unemployment Insurance Periods, Labour Economics 7: 153-80.

[11] Bover, O., Arellano, M. and Bentolila, S. (1998), Unemployment Duration, Benefit Duration and the Business Cycle, CEPR Working Paper No. 1840, London. 
[12] Burdett, K. and Hool, B. (1978), Layoffs, Wages, and Unemployment Insurance, Journal of Public Economics 21, 325-327.

[13] Burdett, K. (1979), Unemployment Insurance as a Search Subsidy: A Theoretical Analysis, Economic Inquiry 17, 333-343.

[14] Card, D. and Levine, P. B. (1994), Unemployment Insurance Taxes and the Cyclical and Seasonal Properties of Unemployment, Journal of Public Economics 53, 1-29.

[15] Card, D. and Levine, P. B. (2002), Extended Benefits and the Duration of UI Spells: Evidence from the New Jersey Extended Benefit Program, forthcoming in Journal of Public Economics; NBER Working Paper No. 6714, 1998.

[16] Carling, K., Edin, P.-A., Harkman, A. and Holmlund, B. (1996), Unemployment Duration, Unemployment Benefits, and Labor Market Programs in Sweden, Journal of Public Economics 59, 313-334.

[17] Carling, K., Holmlund, B. and Vejsiu, A. (1999), Do Benefit Cuts Boost Job Findings? Swedish Evidence from the 1990s, mimeo, University of Uppsala.

[18] Christofides, L. N. and McKenna, C. J. (1996), Unemployment Insurance and Job Duration in Canada, Journal of Labor Economics 14, 286-312.

[19] Devine, J. and Kiefer, N. (1991), Empirical Labor Economics, Oxford: Oxford University Press.

[20] Feldstein, M. S. (1976), Temporary Layoffs in the Theory of Unemployment, Journal of Political Economy 84, 837-857.

[21] Haltiwanger, J. (1984), The Distinguishing Characteristics of Temporary and Permanent Layoffs, Journal of Labor Economics 2, 523-538.

[22] Hesoun, J. (1988), Bericht des Ausschusses für soziale Verwaltung, Beilage zu den Stenographischen Protokollen Des Nationalrates 549, Vienna.

[23] Ham, J. and Rea, S. (1987), Unemployment Insurance and Male Unemployment Duration in Canada, Journal of Labor Economics 5: 325-53. 
[24] Hunt, J. (1995), The Effect of Unemployment Compensation on Unemployment Duration in Germany, Journal of Labor Economics 13, 88-120.

[25] Jurajda, S. (2000), Unemployment Insurance and the Timing of Layoffs, CERGE-EI Discussion Paper No. 46, Charles University, Prague.

[26] Jurajda, S. (2001), Estimating the Effects of Unemployment Insurance Compensation on the Labor Market Histories of Displaced Workers, IZA DP No. 294, IZA, Bonn.

[27] Katz, L. and Meyer, B. (1990), The Impact of the Potential Duration of Unemployment Benefits on the Duration of Unemployment, Journal of Public Economics 41, 45-72.

[28] Lalive, R. and Zweimüller, J. (2000), How Does Maximum Unemployment Duration Affect the Transition Rate to Jobs? Accounting for Policy Endogeneity, mimeo, University of Zürich.

[29] Marimon, R. and Zilibotti, F. (1999), Unemployment vs. Mismatch of Talents: Reconsidering Unemployment Benefits, Economic Journal 109, 266-291.

[30] Moffit, R. and Nicholson, W. (1982), The Effect of Unemployment Insurance on Unemployment: The Case of Federal Supplemental Benefits, Review of Economics and Statistics 64: $1-11$.

[31] Moffit, R. (1985), Unemployment Insurance and the Distribution of Unemployment Spells, Journal of Econometrics 28: 85-101.

[32] Mortensen, D. T. (1977). Unemployment Insurance and Job Search Decisions. Industrial and Labor Relations Review, 30(4): 505-517.

[33] Mortensen, D. T. and Pissarides, C. A. (1994), Job Creation and Job Destruction in the Theory of Unemployment, Review of Economic Studies 61, 397-415.

[34] Mortensen, D. T. and Pissarides, C. A. (1999), New developments in models of search in the labor market, in Ashenfelter, O., and Card, D. (eds), Handbook of Labor Economics Volume 3B. Amsterdam: North-Holland.

[35] Nickell, S. (1982), The Determinants of Equilibrium Unemployment in Britain, Economic Journal 92(367): 555-575. 
[36] Pissarides, C. A. (2000), Equilibrium Unemployment Theory, Cambridge, MA: MIT Press.

[37] Topel, R. (1983), On Layoffs and Unemployment Insurance, American Economic Review, 7(4): 541-559.

[38] Topel, R. (1984), Equilibrium Earnings, Turnover, and Unemployment. New Evidence, Journal of Labor Economics 2(4): 500-522.

[39] Topel, R. (1985), Unemployment and Unemployment Insurance, in Ehrenberg, R. (ed.), Research in Labor Economics, Vol 7, Greenwich, CT: JAI Press.

[40] Van den Berg, G. (1990), Nonstationarity in Job Search Theory, Review of Economic Studies 57, 255-277.

[41] Van den Berg, G., Van der Klaauw, B. and Van Ours, J. C. (1998), Punishing Welfare Recipients for Noncomlicance with Job Search Guidelines, manuscript, Free University Amsterdam.

[42] Winter-Ebmer, R. (1998a), Potential Unemployment Benefit Duration and Spell Length: Lessons from a Quasi-Experiment in Austria, Oxford Bulletin of Economics and Statistics 60: $33-45$.

[43] Winter-Ebmer, R. (2002), Benefit Duration and Unemployment Entry: QuasiExperimental Evidence for Austria, forthcoming in European Economic Review; mimeo, Univerisity of Linz.

[44] Wolpin, K. I. (1995), Empirical methods for the study of labor force dynamics, Luxembourg: Harwood Academic Publishers. 
Figure 1 : Relative unemployment rate and relative incidence of long-term unemployment: ages 50-59/ages $40-49$

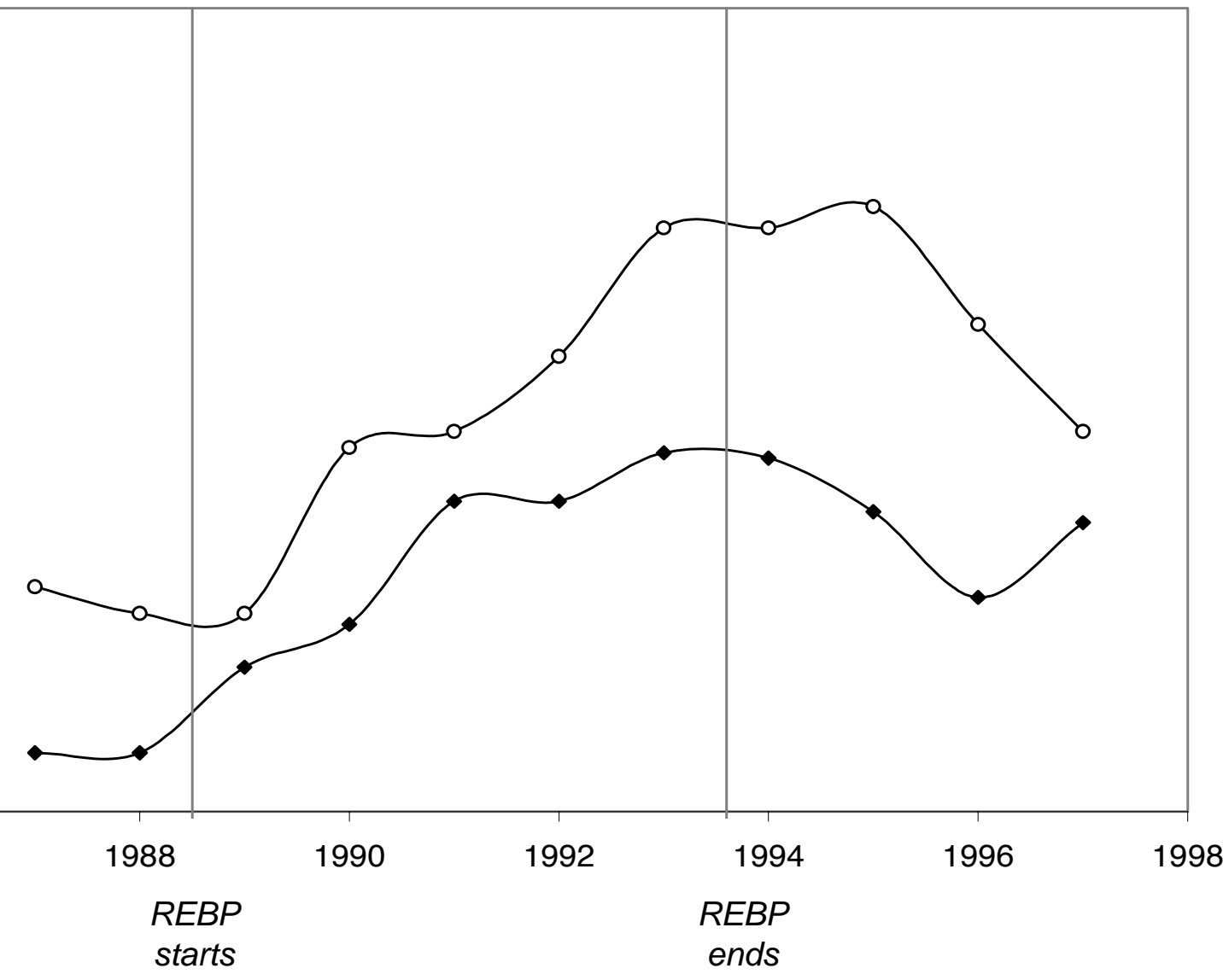

- relative unemployment rate ages(50-59)/ages(40-49)

- - relative incidence of longterm unemployment ages(50-59)/ages(40-49) 

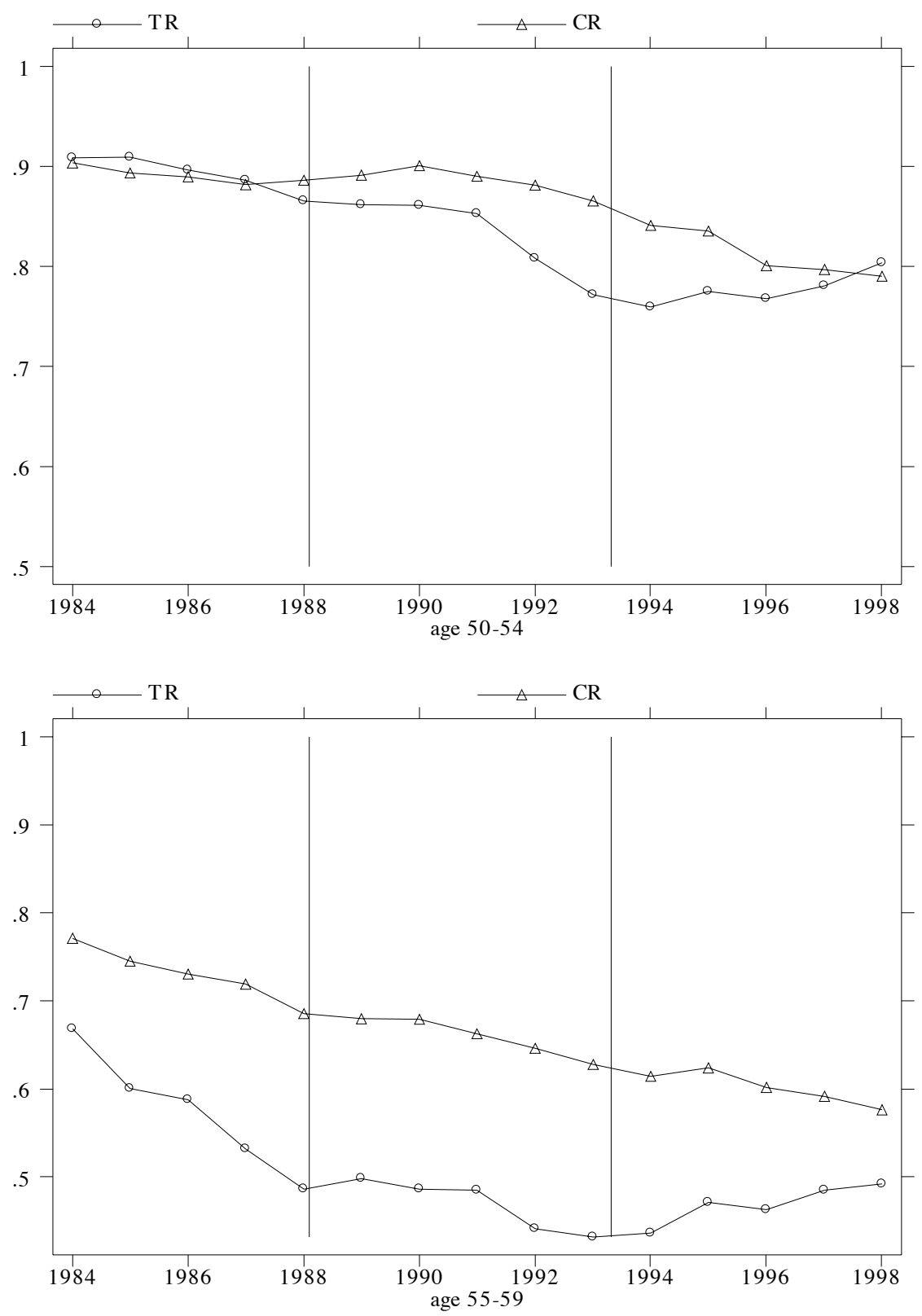

Figure 2. The effect of REBP on employment (\% of population) 

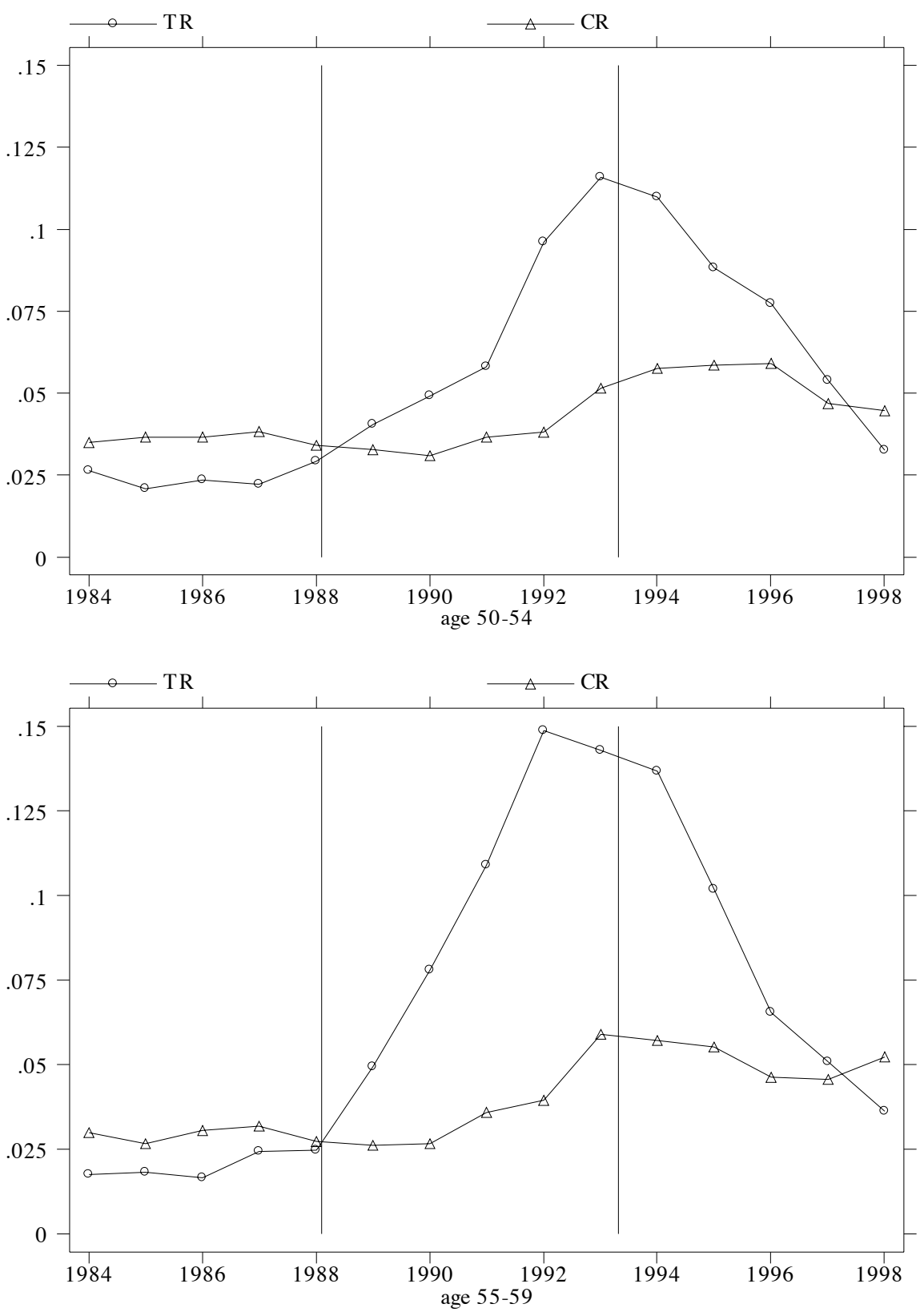

Figure 3. The effect of REBP on unemployment (\% of population) 


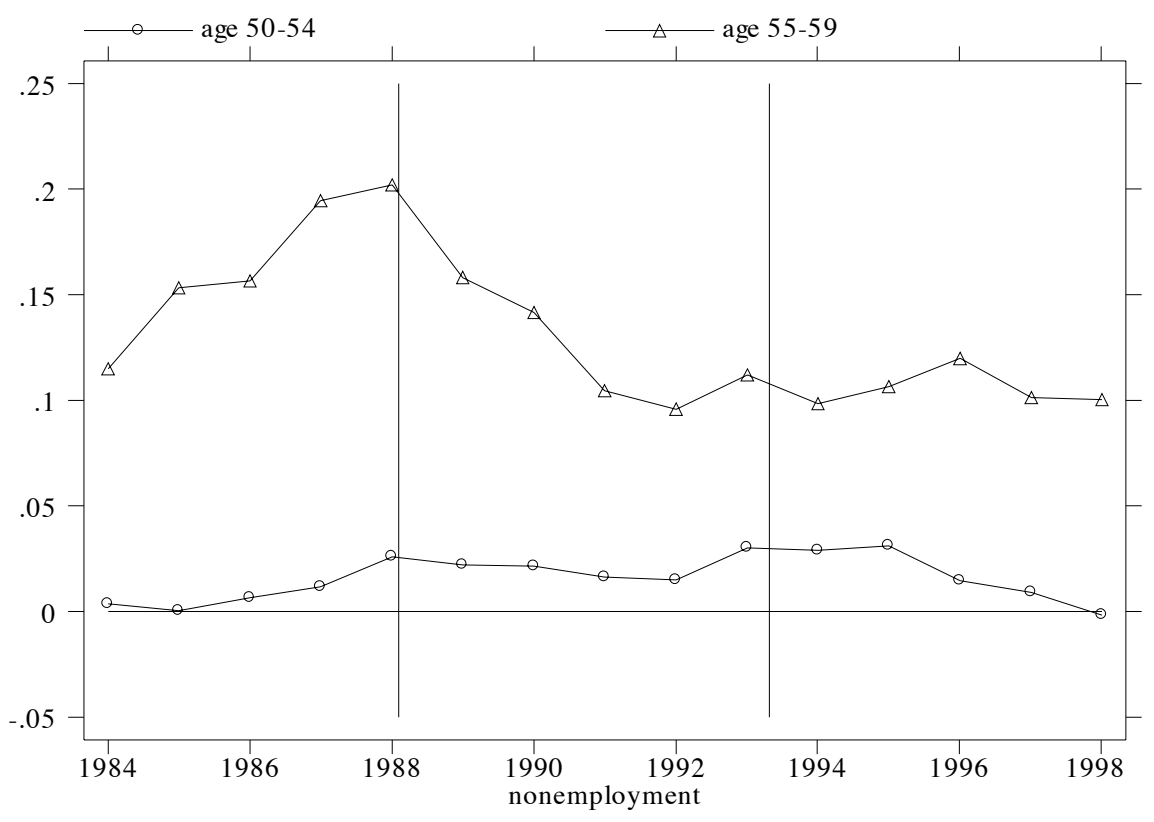

Figure 4. Regional difference in the nonemployment ratio, ages 50-59 

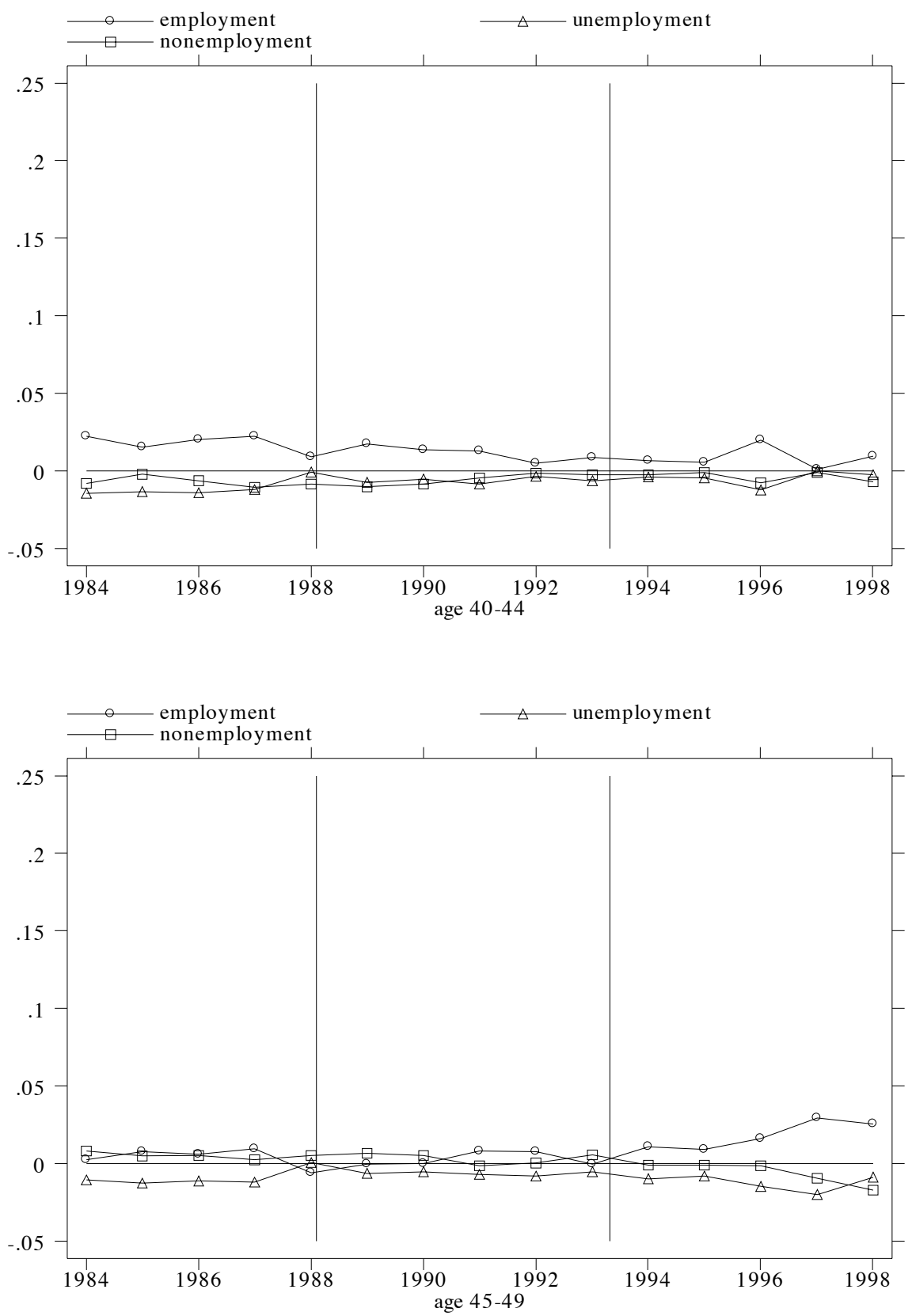

Figure 5. Regional differences, ages 40-49 

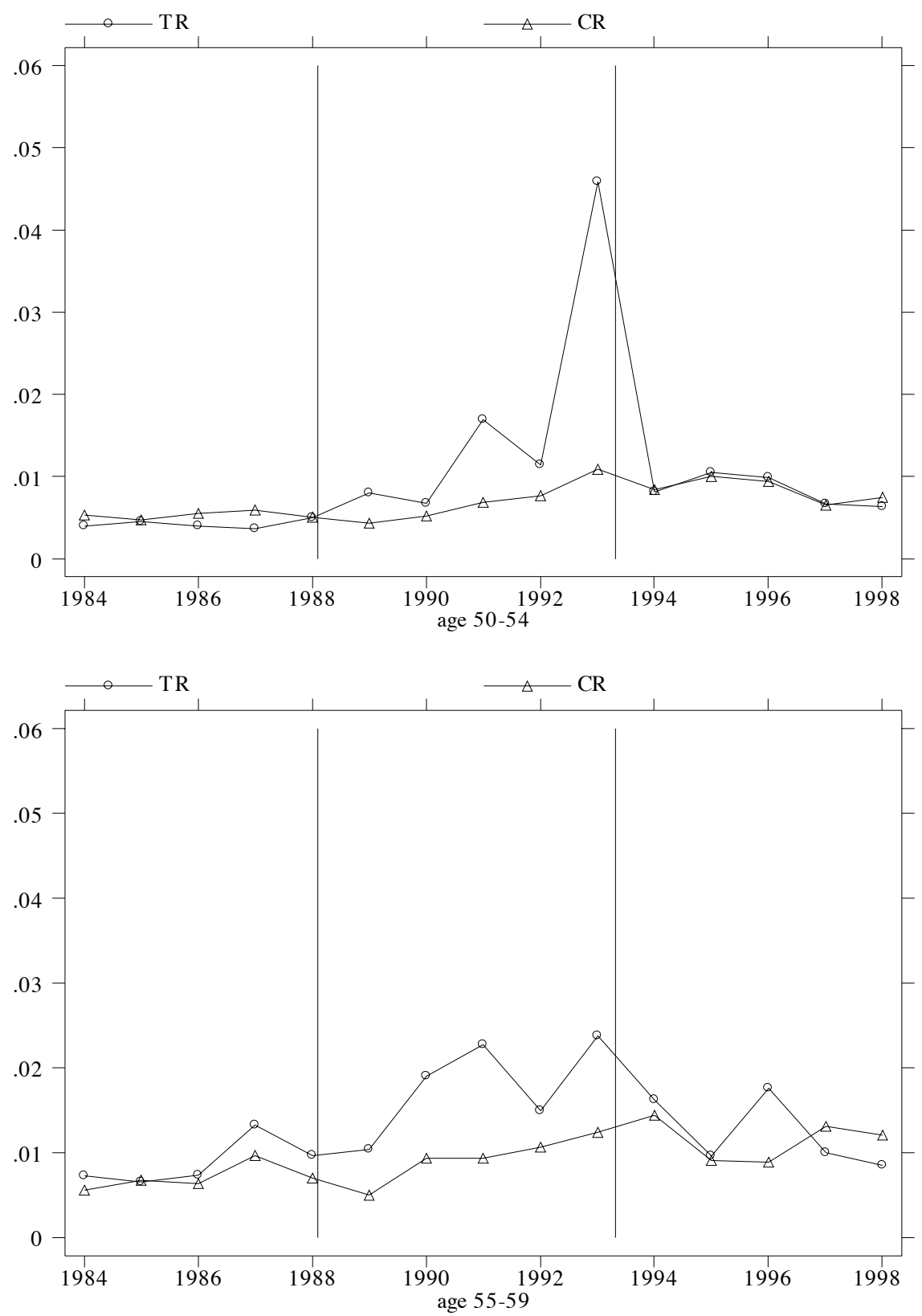

Figure 6. The effect of REBP on unemployment inflow (\% of employment, per quarter) $\mathrm{TR}=$ treated regions; $\mathrm{CR}=$ control regions 


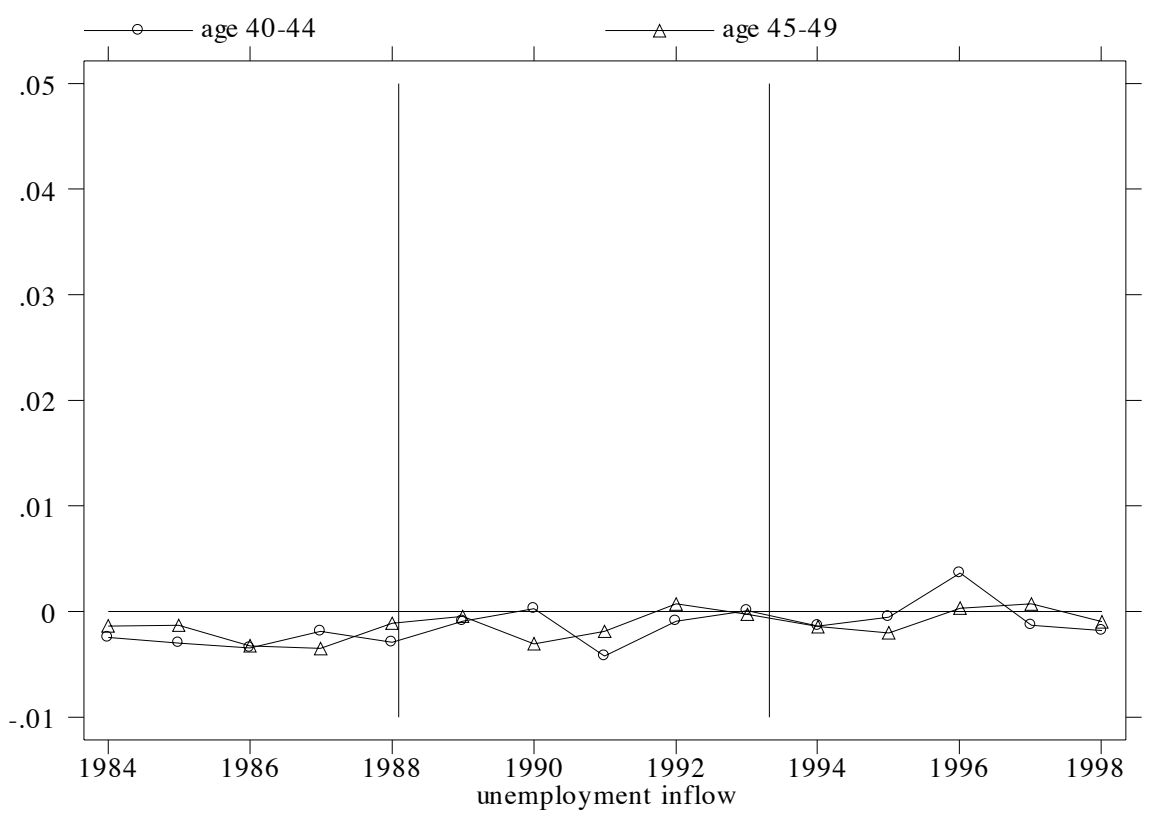

Figure 7. Regional difference in unemployment inflow rate, ages 40-49 

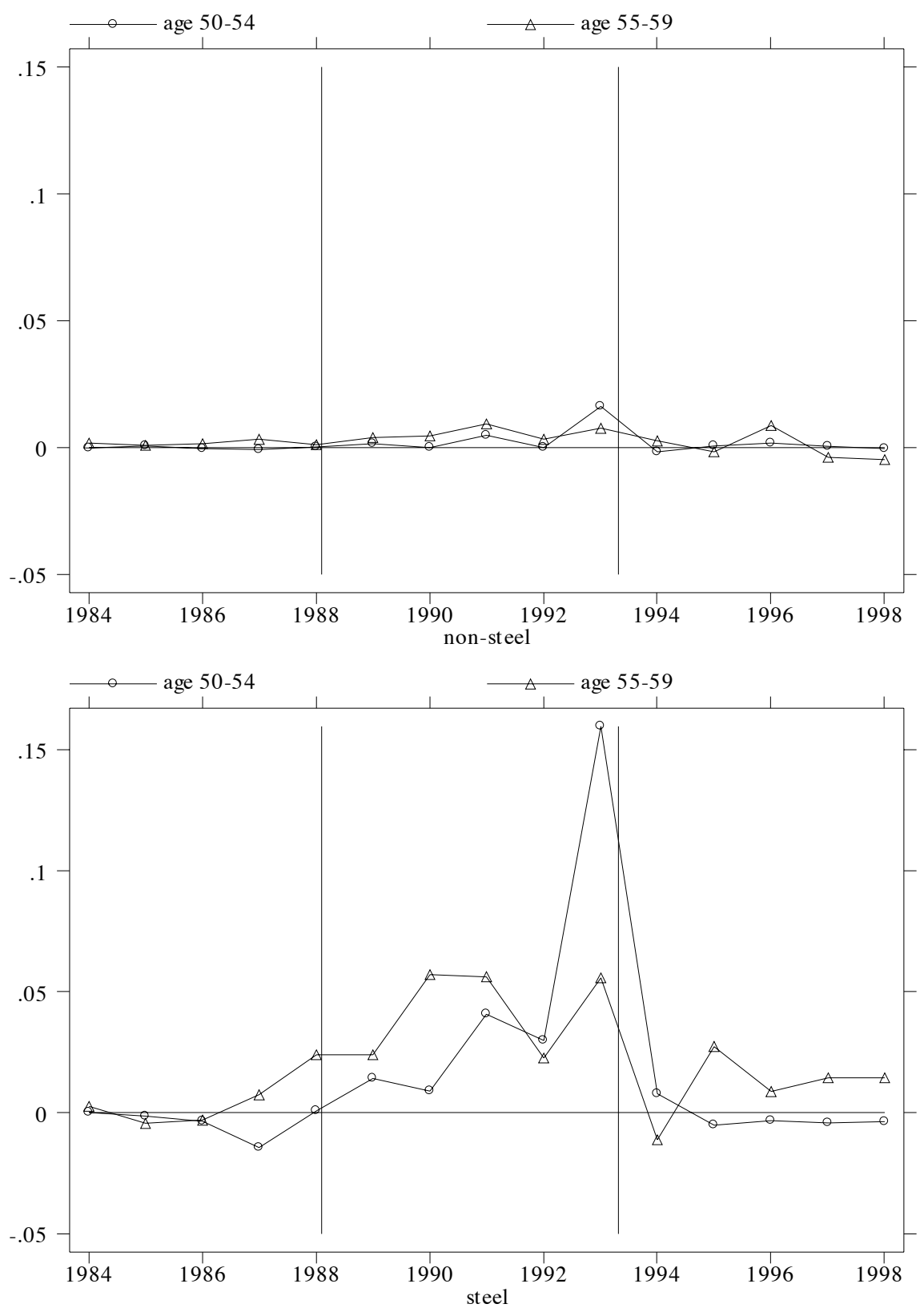

Figure 8. Regional difference in unemployment inflow rate steel workers vs non-steel workers. 
Birth cohort 1938

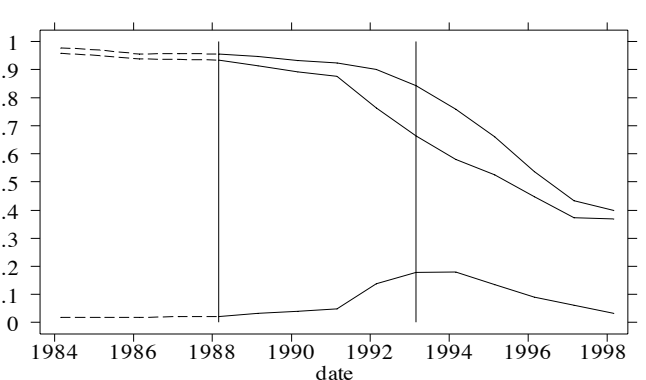

Birth cohort 1941

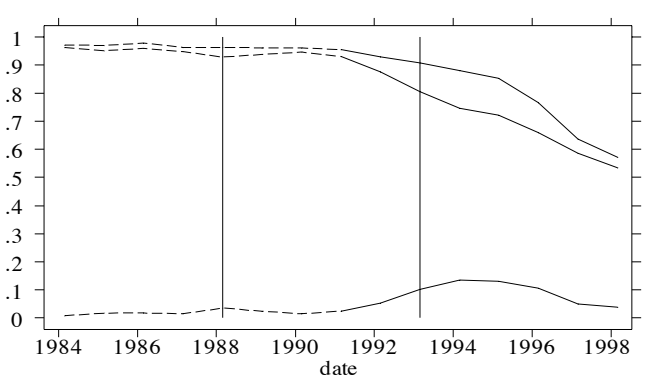

Birth cohort 1944

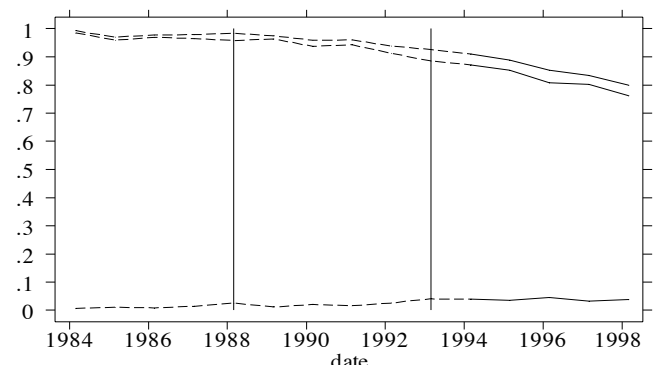

CR

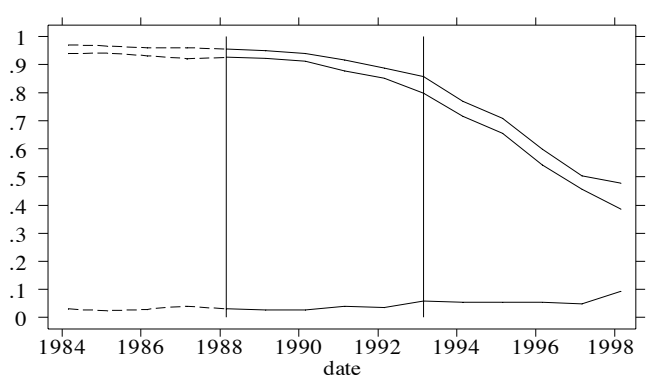

$\mathrm{CR}$

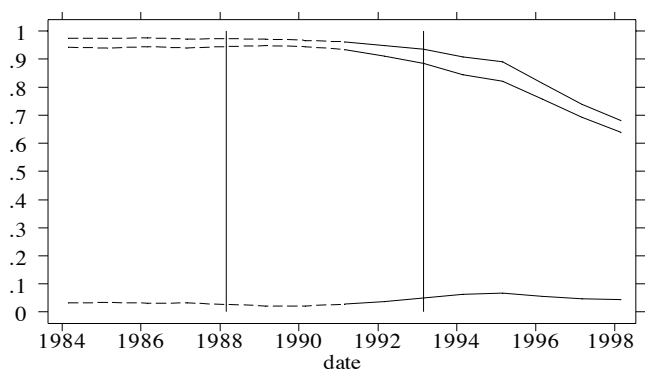

CR

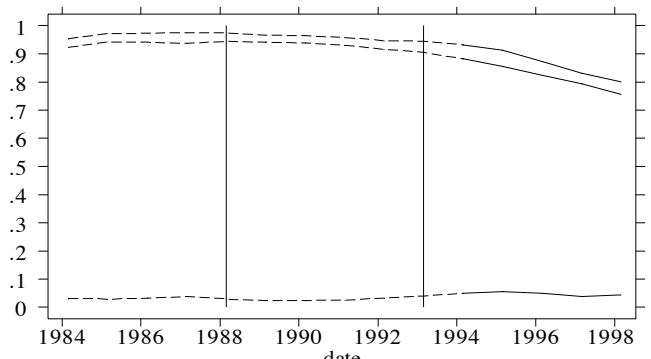

Figure 9. A life-cycle perspective

unemployment ( $\mathrm{u}$; bottom), employment (e; middle), and labor force participation ( $\mathrm{u}+\mathrm{e}$; top) solid line $=$ aged 50 or older 
1988

1993

Overall unemployment rate

5.3

6.8

Age $40-49$

4.7

6.0

Age $50-54$

5.1

9.9

Age 55 - 59

5.4

11.1

Source: Arbeitsmarktservice Austria. 


\begin{tabular}{rrrr} 
Before & During & After & Total \\
1988 & 1991 & 1994 & \\
& & & \\
\hline
\end{tabular}

A. Treated regions

$\begin{array}{lrrrr}\text { Age 55-59 } & 6.90 & 7.82 & 6.84 & 7.19 \\ \text { Age 50-54 } & 19.72 & 15.33 & 11.78 & 15.39 \\ \text { Age 45-49 } & 18.51 & 16.42 & 14.57 & 16.64 \\ \text { Age 40-44 } & 17.02 & 15.59 & 13.79 & 15.49\end{array}$

B. Control regions

\begin{tabular}{lllll} 
Age 55-59 & 3.89 & 3.66 & 3.90 & 3.82 \\
Age 50-54 & 4.52 & 4.19 & 4.00 & 4.20 \\
Age 45-49 & 4.14 & 4.04 & 4.13 & 4.10 \\
Age 40-44 & 4.40 & 4.78 & 4.51 & 4.57 \\
& & & & \\
\hline & 7.41 & 6.87 & 6.20 & 6.83 \\
\hline
\end{tabular}

Notes: May 10 of respective year.

Source: Own calculation based on Austrian social security data. 


\begin{tabular}{|c|c|c|}
\hline All spells & Treated spells & Non-treated spells \\
\hline$[\%]$ & {$[\%]$} & {$[\mathrm{N}]$} \\
\hline
\end{tabular}

Duration

$\begin{array}{lrrrrrr}>=3 \text { months } & 79241 & 39.53 & 12251 & 51.72 & 140116 & 38.73 \\ \text { >= } 6 \text { months } & 21684 & 18.98 & 9162 & 38.68 & 63998 & 17.69 \\ \text { >= } 9 \text { months } & 10998 & 13.35 & 8236 & 34.77 & 43232 & 11.95 \\ \text { >= } 12 \text { months } & 16790 & 10.50 & 7497 & 31.65 & 32958 & 9.11 \\ \text { >= } 24 \text { months } & 23671 & 6.14 & 5493 & 23.19 & 18161 & 5.02\end{array}$

Mean completed duration (days)

139.51

315.08

128.68

Exit status

$\begin{array}{lrrrrrr}\text { Employment } & 291117 & 75.52 & 12885 & 54.40 & 278232 & 76.91 \\ \text { Long term sickness } & 29272 & 7.59 & 3391 & 14.32 & 25881 & 7.15 \\ \text { Retirement } & 14860 & 3.86 & 3010 & 12.71 & 11850 & 3.28 \\ \text { Olf } & 40302 & 10.46 & 2535 & 10.70 & 37767 & 10.44 \\ \text { Censored } & 9912 & 2.57 & 1866 & 7.88 & 8046 & 2.22\end{array}$

Observations

385463

100.00

23687

100.00

$361776 \quad 100.00$

Notes: Sample covers all unemployment spells started between 1986 and 1995 of male individuals aged 45 to 54 .

Source: Own calculations based on Austrian social security data. 
All spells $\quad$ Treated spells $\quad$ Non-treated spells

Mean completed duration (days)

$\begin{array}{llll}\text { Steel workers } & 234.07 & 504.49 & 172.68 \\ \text { Non-steel workers } & 128.46 & 220.52 & 124.30\end{array}$

Exit to employment (\% of total)

$\begin{array}{llll}\text { Steel workers } & 57.57 & 30.63 & 64.37 \\ \text { Non-steel workers } & 77.72 & 67.62 & 78.19\end{array}$

Observations

Steel workers

42010

8468

33542

Non-steel workers

343453

15219

328234

Notes: $\quad$ Sample covers all unemployment spells started between 1986 and 1995 of male individuals aged 45 to 54 .

Source: Own calculations based on Austrian social security data. 
TR1

Treated
TR2

Treated

Non-treated

332.13

128.68

Mean completed duration (days)

178.45

51.96

76.91

Exit to employment (\% of total)

75.22

2482

21205

361776

Notes: Sample covers all unemployment spells started between 1986 and 1995 of male individuals aged 45 to 54 . TR1 (TR2) refers to regions entitled to REBP from 1988-1991 (1988-1993).

Source: Own calculations based on Austrian social security data. 


\begin{tabular}{lllccc} 
& & \multicolumn{3}{c}{ Time } & \\
& Before & During & After & Difference & Time \\
Location / year & policy & policy & policy & During & Difference \\
& & & & & \\
\hline
\end{tabular}

A. Workers aged 50-54

Treated regions

$6.566 \quad 6.839$

6.821

0.273

$-0.018$

821

1611

1019

Control regions

6.603

6.734

6.849

0.131

0.115

2725

3108

3373

Regional difference

$-0.036$

0.105

$-0.029$

0.141

$-0.134$

B. Workers aged 45-49

Treated regions

$\begin{array}{lllll}6.598 & 6.709 & 6.759 & 0.111 & 0.050 \\ 1094 & 1047 & 1089 & & \end{array}$

Control regions

$$
6.622
$$

6.740

6.795

0.118

0.054

3159 3569

3798

Regional difference

$-0.024$

$-0.031$

$-0.036$

$-0.007$

$-0.005$

Difference-in-difference-in-difference estimate (DiDiD)

$\begin{array}{cc}0.149 & -0.129 \\ (0.018) & (0.020)\end{array}$

Notes: Standard error in parenthesis. Log of daily real wage in AS.

Source: Own calculations, based on Austrian social security data. 


\begin{tabular}{|c|c|c|c|c|}
\hline & \multicolumn{2}{|c|}{ Change in Median } & \multicolumn{2}{|c|}{$\begin{array}{l}\text { Change in Difference } \\
\text { 7th decile-3rd decile }\end{array}$} \\
\hline & During policy & After policy & During policy & After policy \\
\hline Unemployment entrants & $\begin{array}{c}0.149 \\
(0.018)\end{array}$ & $\begin{array}{l}-0.129 \\
(0.020)\end{array}$ & $\begin{array}{c}0.153 \\
(0.026)\end{array}$ & $\begin{array}{l}-0.107 \\
(0.028)\end{array}$ \\
\hline Exits from unemployment & $\begin{array}{c}0.029 \\
(0.020)\end{array}$ & $\begin{array}{l}-0.021 \\
(0.023)\end{array}$ & $\begin{array}{c}0.033 \\
(0.028)\end{array}$ & $\begin{array}{l}-0.061 \\
(0.032)\end{array}$ \\
\hline Employed & $\begin{array}{l}-0.011 \\
(0.003)\end{array}$ & $\begin{array}{l}-0.026 \\
(0.003)\end{array}$ & $\begin{array}{c}0.027 \\
(0.005)\end{array}$ & $\begin{array}{c}0.017 \\
(0.005)\end{array}$ \\
\hline
\end{tabular}

Notes: Standard error in parentheses; difference-in-difference-in-difference estimates.

Source: Own calculations, based on Austrian social security data. 